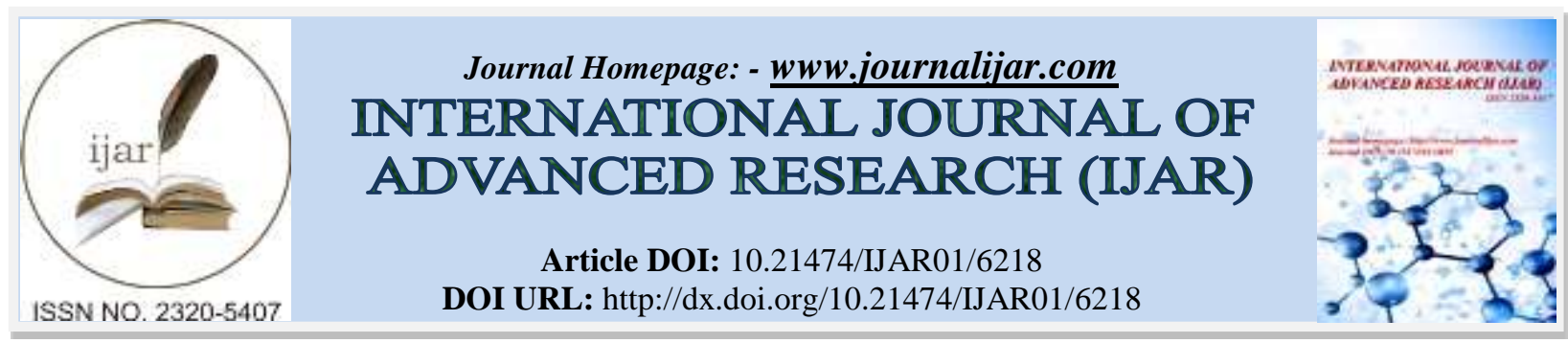

RESEARCH ARTICLE

\title{
EFFECT OF RECYCLED AGGREGATE ON THE COMPRESSIVE BEHAVIOR OF SHORT CONCRETE COLUMNS.
}

Hanaa Shihab Hammadi.

Univesity Of Kufa, Department of Engineering Affairs.

\section{Manuscript Info}

Manuscript History

Received: 05 November 2017

Final Accepted: 07 December 2017

Published: January 2018

Key words:-

Concrete; Columns; Confined concrete;

Recycled aggregate; Reinforcement.

\section{Abstract}

In this study, 12 specimens with three different lateral reinforcement ratios $(\rho=0.022,0.012$ and 0.007$)$ and four $\mathrm{RG}$ replacement ratios $(0 \%$, $30 \%, 50 \%$ and $100 \%$ ) were prepared and tested under pure axial load in order to investigate the influence of recycled coarse aggregate (RG) and lateral tie reinforcement ratio $(\rho)$ on the compressive behavior of a confined recycled aggregate concrete (RAC) column. The experimental data obtained from the tests are reported and compared with the predicted values obtained from the widely accepted Mander's confined concrete model developed for conventional confined concrete to assess applicability of the model to recycled aggregate concrete. The results showed that the effect of RG on the compressive behavior of the RAC was negligible at low stress level, and it began to appear as the load increased at load levels above about $35 \%$ of Peak, regardless of $\rho$. The slope of the normalized compressive strength (fcc' /fco') and normalized corresponding strain ( $\varepsilon \mathrm{cc} / \varepsilon \mathrm{co}$ ) against $\rho$ showed that the effect on the stress and strain enhancement in the RG-30 series, and the smallest effect in the RG-50 series. The ratios of experimental values to those predicted from Mander's model, f'cc_exp/f'cc_model and $\varepsilon c c \_$exp/\&cc_model, showed that the model tended to give unconservative strength (f'cc) and strain ( $\varepsilon \mathrm{cc})$ values for the RAC columns.

Copy Right, IJAR, 2018,. All rights reserved.

\section{Introduction:-}

he need to recycle old construction materials has been well established over the last few decades by government agencies and the construction industry due to the increasing cost of waste storage and the depletion of natural resources [1]. Among the numerous construction waste materials, old concrete, in particular, is a promising source of recycled aggregate with sufficient quality for civil engineering applications with moderate performance requirements $[2,3]$. While most of the studies on the subject thus far have focused on the processing of old concrete and the properties of recycled aggregate concrete (RAC), only a limited number of studies have reported the performance of structural members made of RAC: beam [4-6], column [7], joint [8], and frame [9]. Although a direct comparison of the results from different studies is difficult due to a lack of coherent concrete constituents, the results generally indicate that the strength decreases with slight increase in the corresponding strain as recycled aggregate content in the concrete increases. his strength decrement was attributed to a weak interface between the new mortar and the recycled aggregate and between the adhered mortar and the recycled aggregate [10,11]. he reduction in strength due to RG can be of set by two approaches: adjusting proportions of concrete constituents or providing proper 
reinforcement. he choice between the two approaches should be made based on the required structural performance and cost. Low tensile-high compressive strength cementitious materials typically exhibit brittle behavior, but their ductility and compressive strength improves significantly when subjected to favorable biaxial pressure [12]. For the past few decades, the compressive behavior of concrete confined by properly arranged lateral reinforcements has been extensively studied by many researchers. he effects of various parameters, including concrete strength, amount of lateral reinforcement, lateral reinforcement configuration, dimensions, and cross section geometry, on confined concrete behavior are now sufficiently understood. As a result, the use of confined concrete columns has become a common practice for seismic resistant design [13]. Nevertheless, as aforementioned, most of the confined concrete studies focused on concrete containing virgin aggregate. Recently, the performance of reinforced RAC frame, which satisfies the requirement set by the ACI earthquake resistant design code and the Chinese standard, has been reported by Xiao et al. [9]. Although Xiao's test demonstrated the potential use of reinforced recycled aggregate in the seismic resistance frame, few studies have investigated the effect of recycled aggregate on confined concrete members, of which behavior is critical for modern, high performance design. Hence, in an attempt to broaden the use of RAC, the influences of the recycled coarse aggregate (RG) content and the volumetric ratio of lateral reinforcement on the compressive behavior of confined columns subjected to concentric load are experimentally investigated here. In addition, the applicability of the existing design model [14] is assessed against the experimental results.

\section{Experimental Program:- \\ Materials:-}

River sand and crushed gravel were used as natural fine (NS) and natural coarse aggregate (NG), respectively. he recycled coarse aggregate (RG) was obtained from 5 concrete (at least 20 years old, with a typical design compressive strength of $18 \sim 20 \mathrm{MPa}$ ) collected from an apartment redevelopment site in Korea. The RG was separated from the cement matrix through multiple crushing stages while the loose fine particles were washed of the surface of the RG to minimize the effect of the fines generated during the crushing [15]. he resulting RG only contained small amounts of adhered old mortar and had similar physical properties to those of the NA, as shown in Table 1. he RG used in this study meets the Korean Industrial Standard KS F2573 for recycled aggregate for structural concrete use. For the binder, locally manufactured, Type I Portland cement satisfying ASTM C150 specifications was chosen for the concrete mix (Table 1).Concrete mixes were prepared by replacing NG with RG at four different replacement ratios of $0 \%, 30 \%, 50 \%$ and $100 \%$ as shown in Table 2. The amounts of high performance water reducing admixture (polycarboxylic acid type) and air entraining agents (neutralized vinsol resin type) were adjusted to achieve the target slump and air content of $200 \mathrm{~mm}$ and $6 \%$ respectively. he average compressive strength of the control concrete the tests was $30 \sim 34 \mathrm{MPa}$ (Table 2). For each steel reinforcement bar size, three steel samples were tested under tension. he average yield strength, yield strain, Young's modulus values from the test, and specified ultimate strength of the steel rebar are given in Table 3.

Table 1:- Physical properties of aggregates

\begin{tabular}{|l|l|l|l|l|l|}
\hline Type & Max & $\begin{array}{l}\text { Specific } \\
\text { gravity }\end{array}$ & Water absorption & Fineness modulus & Bulk density (kgf/m3) \\
\hline NG & & 2.6 & 1.63 & 6.52 & 1642 \\
\hline RG & 25 & 2.48 & 1.93 & 6.77 & 1615 \\
\hline NS & 5 & 2.53 & 1.62 & 2.79 & 1455 \\
\hline
\end{tabular}

Table 2:- Mix proportions and wet concrete properties.

\begin{tabular}{|c|c|c|c|c|c|c|c|}
\hline Specimen & W/C & S/A & AD & \multicolumn{2}{|c|}{ Init Weight $\left(\mathrm{N} / \mathrm{m}^{3}\right)$} & Slump & Air content (\%) \\
\hline & $\%$ & $\%$ & $\begin{array}{l}\% \\
\mathrm{~W}\end{array}$ & $\mathbf{C}$ & NGRG & $\mathbf{N S}(\mathbf{m m})$ & \\
\hline RG-0-30 & & & & \multirow[t]{3}{*}{983.7} & \multirow[t]{3}{*}{$\mathbf{0}$} & \multirow[t]{3}{*}{205} & \multirow[t]{3}{*}{5.5} \\
\hline RG-0-65 & & & & & & & \\
\hline RG-0-100 & & & & & & & \\
\hline RG-30-30 & & & & \multirow[t]{3}{*}{688.6} & \multirow[t]{3}{*}{301.1} & \multirow[t]{3}{*}{200} & \multirow[t]{3}{*}{5} \\
\hline RG-30-65 & & & & & & & \\
\hline RG-30-100 & & & & & & & \\
\hline
\end{tabular}




\begin{tabular}{|c|c|c|c|c|c|c|c|c|c|}
\hline RG-50-30 & 50 & 42 & 0.6 & 175 & 350 & & 726.7 & & \\
\hline RG-50-65 & & & & & \multirow[t]{2}{*}{491.9} & \multirow[t]{2}{*}{501.8} & & \multirow[t]{2}{*}{195} & \multirow[t]{2}{*}{6.5} \\
\hline RG-50-100 & & & & & & & & & \\
\hline RG-100-30 & & & & & \multirow[t]{3}{*}{$\mathbf{0}$} & \multirow[t]{3}{*}{1003.5} & & \multirow[t]{3}{*}{190} & \multirow[t]{3}{*}{6} \\
\hline RG-100-65 & & & & & & & & & \\
\hline RG-100-100 & & & & & & & & & \\
\hline
\end{tabular}

Table 3:- Mechanical properties of deformed steel bars.

\begin{tabular}{|l|l|l|l|l|}
\hline Type & Fyh $($ MPa $)$ & Es $($ GPa $)$ & ey $(\times 10-6)$ & Fsu $($ MPa $)$ \\
\hline D13 & 420 & 183 & 2,945 & 630 \\
\hline D6 & 324 & 240 & 2,365 & 590 \\
\hline
\end{tabular}

Column specimens:-

A total of 12 specimens of concrete columns were prepared with three different lateral reinforcement ratios ( $\rho=0.022,0.012$, and 0.007$)$ and the four different RG replacement ratio. he tie hoop spacing was set at $30 \mathrm{~mm}$ $(\rho=0.022), 65 \mathrm{~mm}(\rho=0.012)$ and $100 \mathrm{~mm}(\rho=0.007)$ to satisfy the minimum tie hoop spacing specified by the two standards: D/2 $(100 \mathrm{~mm})$, based on the earthquake-resistant design of the Architectural Institute of Korea; and D/4 $(50 \mathrm{~mm})$, based on the earthquake-resistant design of the ACI Committee 318-05. he details of the test specimens are listed in Table 4, and the detailed dimensions of the column specimens are illustrated in Figure 1. All the specimens shared the same dimensions of $200 \mathrm{~mm} \times 200 \mathrm{~mm}$ cross section and $600 \mathrm{~mm}$ height. he upper and lower $100 \mathrm{~mm}$ of the specimens along the length were reinforced internally with tie hoops spaced at $20 \mathrm{~mm}$ and fitted externally with a carbon fiber reinforced plastic wrap to prevent the bearing failure of the specimen ends prior to failure of the test area of the specimens (Table 4 and Figure 2). he tie hoops were made of D6 (6 mm nominal diameter) rebar and one D13 (13 mm nominal diameter) longitudinal rebar was placed at each corner of the column. he hooks of the tie hoops were anchored with $135^{\circ}$ bending, with an extended length of $6 \mathrm{db}$, which is longer than the minimum length required by the ACI Code. he cover depth of concrete from the center of the tie hoops was $17 \mathrm{~mm}$, and the cross section of the core surrounded by the center of a tie hoop was $166 \mathrm{~mm} \times 166 \mathrm{~mm}$. he ratio of the core area to the entire cross section was fixed at $69 \%$ for all specimens.

Table 4:- Column specimens.

\begin{tabular}{|c|c|c|c|c|}
\hline \multirow[t]{2}{*}{ Specimen } & \multirow{2}{*}{$\begin{array}{l}\text { Section } \\
(\mathbf{m m})\end{array}$} & \multicolumn{2}{|l|}{ Tie hoop } & \multirow{2}{*}{$\begin{array}{l}\text { Longitudinal } \\
\text { rebar ratio }\end{array}$} \\
\hline & & Spacing & Volumetric ratio & \\
\hline RG-0-30 & \multirow[t]{12}{*}{$200 \times 200$} & 30 & 0.012 & \multirow{12}{*}{$\begin{array}{l}\text { 8-D13 } \\
-0.025\end{array}$} \\
\hline RG -0-65 & & 65 & 0.006 & \\
\hline RG -0-100 & & 100 & 0.004 & \\
\hline RG-30-30 & & 30 & 0.012 & \\
\hline RG-30-65 & & 65 & 0.006 & \\
\hline RG-30-100 & & 100 & $\mathbf{0}$ & \\
\hline RG-50-30 & & 30 & $\mathbf{0}$ & \\
\hline RG-50-65 & & 65 & 0.006 & \\
\hline RG-50-100 & & 100 & 0.004 & \\
\hline RG-100-30 & & 30 & 0.012 & \\
\hline RG-100-65 & & 65 & 0.006 & \\
\hline RG-100-100 & & 100 & 0.004 & \\
\hline
\end{tabular}

Note:

Type of aggregate: RG (Recycled aggregate)

Replacement ratio of RGs: 0 (:0\%), 30 (:30\%), 50 (:50\%), 100 (:100\%)

Tie hoop spacing: 30 (:30 mm), 65 (:65 mm), $100(: 100 \mathrm{~mm})$ 

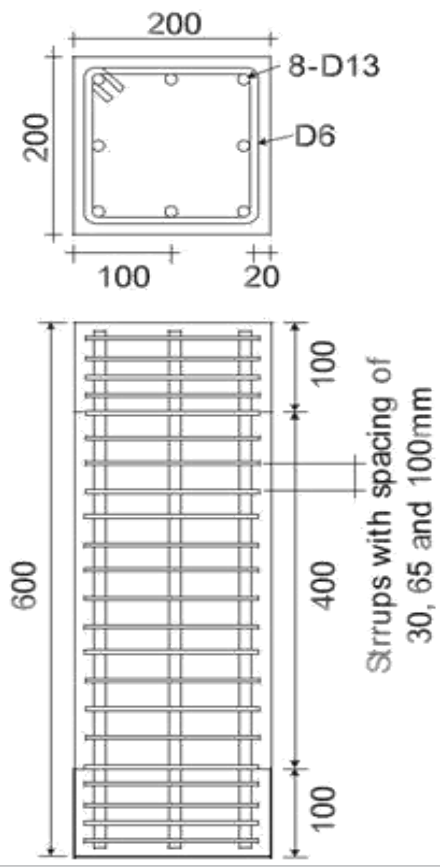

Figure 1:- Specimen geometry and bar arrangement detail.

\section{Test setup and measurement:-}

A square plate with a semicircular seat was placed on the top of the specimen to prevent any moment load on the specimen by eccentric load prior to application of the axial load. he loading was applied under load control such that the initial rate of displacement was about $0.30 \mathrm{~mm} / \mathrm{min}$, equivalent to $0.00075 \mathrm{strain} / \mathrm{min}$. As load increased the loading rate was carefully adjusted in order to trace the unloading part of the curves. he loading was stopped when the post- peak descending curve shape became apparent or when stable loading could no longer be attained. he deformation measurements were recorded at constant time intervals using a data logger (TML TDS- 303). he axial deformation of the specimen was recorded from the four linear variable differential transducers (LVDT) installed at each corner of the specimen. he average deformation value from the four LVDTs was calculated and used as the axial deformation value. We note here that the fixtures with vertical rigid rod with horizontal end plate placed above the LVDTs were attached to the top of the specimen in order to measure compressive deformation over the entire length of the specimen. 


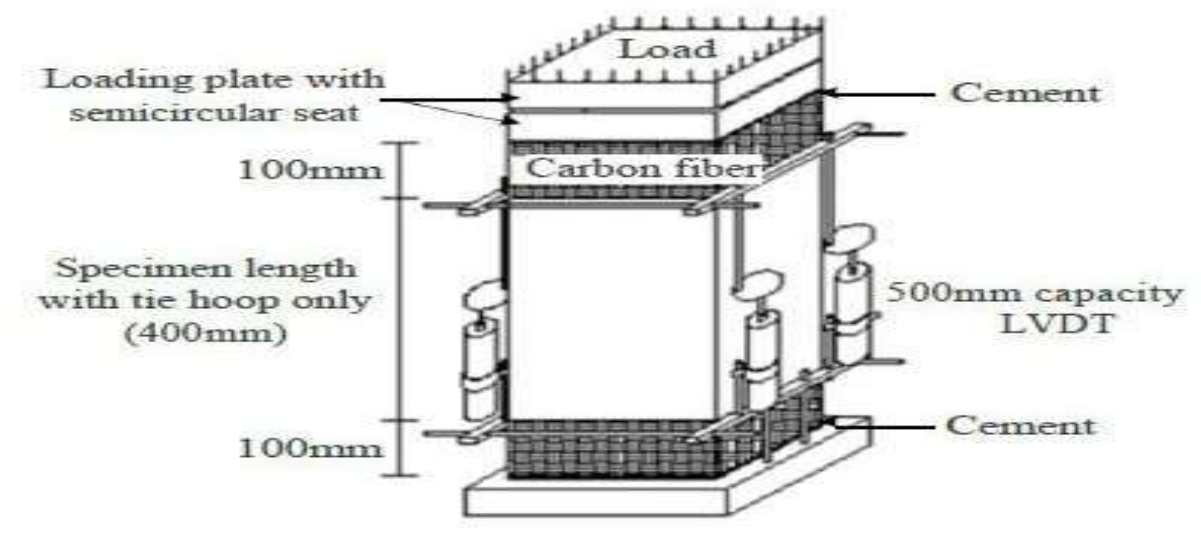

\section{Schematic illustration of loading test and specimen}

Figure 2:- Test set up method: (a) Schematic illustration of loading test and specimen.

Table 5:- Test results.

\begin{tabular}{|c|c|c|c|c|c|}
\hline Specimen & f'co (MPa) & $\operatorname{Pcr}(k N)$ & ecr & Ppeak (kN) & ecc \\
\hline RG-0-30 & 34.1 & 1,190 & 0.00245 & 1816 & 0.00476 \\
\hline RG-0-65 & & 1,110 & 0.00282 & 1712 & 0.00382 \\
\hline RG-0-100 & & 1,086 & 0.00138 & 1675 & 0.00339 \\
\hline RG-30-30 & 33.5 & 1,150 & 0.00214 & 1815 & 0.00495 \\
\hline RG-30-65 & & 1,050 & 0.00121 & 1638 & 0.00347 \\
\hline RG-30-100 & & 976 & 0.00153 & 1538 & 0.00325 \\
\hline RG-50-30 & 32.4 & 1,029 & 0.00188 & 1785 & 0.00499 \\
\hline RG-50-65 & & 1,009 & 0.001 & 1738 & 0.00368 \\
\hline RG-50-100 & & 882 & 0.00121 & 1677 & 0.00372 \\
\hline RG-100-30 & 30.5 & 999 & 0.00146 & 1727 & 0.00453 \\
\hline RG-100-65 & & 985 & 0.00126 & 1622 & 0.00375 \\
\hline RG-100-100 & & 701 & 0.00078 & 1582 & 0.00326 \\
\hline
\end{tabular}

\section{Results and Discussion:-}

\section{Failure modes:-}

The maximum (Peak) and critical (Pcr) loads at which significant cover spalling occurred are listed in Table 5. the first visible crack appeared in a vertical direction near a corner edge at $60 \sim 80 \%$ of Peak, as the cover concrete deterioration worsened, and Ppeak was reached at a strain much greater than those of the unconfined concretes. Subsequently, with further increase in the applied load, the cover concrete of the specimens began to spall. For a given tie hoop spacing, the rate of cover concrete spalling was proportional to the RG replacement ratio (Figure 3). After localized crack damage was observed on a side of the column, notable spalling of the cover concrete occurred with a gradual decrease in the applied load. Spalling of the cover concrete occurred at a lower applied load in RAC than in natural aggregate concrete (NAC). he lower Pcr of RAC can be attributed to the relatively higher water absorptiveness of RG, which should have created a steeper moisture content gradient from the cover layer to the interior layer of the specimen. In turn, the moisture content gradient due to RG can cause higher incompatible drying shrinkage between the interior and exterior RAC, compared to that of NAC [16], thereby facilitating the cover was spalling. Furthermore, the lower bond strength between the rebar and RAC than NAC [17] also contribute to the lower cover spalling load and the faster rate of cover degradation in RAC compared to those of the NAC columns. 


\section{Compressive stress-strain curves:-}

Stress-strain curves of the plain concrete cylinders with different RG contents up to the maximum stress are shown in Figure 3. he curves show a greater loss of stiffness at a given load level with increasing RG replacement ratio. he effect of RG on the compressive behavior of concrete became apparent at about $10 \mathrm{MPa}$, which is $31 \%$ of the average strength of the four specimens, similar to the result reported by Topcu IB, et al. [18]. he axial compression tests of the laterally reinforced RAC columns showed that their compressive behavior in almost entire strain range, both the ascending and descending branches of the stress-strain curve, is affected by the RG, as shown in Figure 4 . In all the specimens, the ascending branch of the stress-strain curves of the column containing RG showed a smaller increase in stress per given strain increase than that of the concrete column containing NA only, and the Ppeak value of the RAC column was lower than that of the NAC column. he lower stiffness of RAC compared to that of NAC can be attributed to presence of micro- cracks in the RG and adhered mortar on the RG surface $[19,20]$. At low load below $600 \mathrm{kN}(15 \mathrm{MPa})$, the specimens having the same tie hoop spacing showed almost identical compressive behavior, regardless of the RG replacement ratio. However, the compressive behavior of the specimens with different RG replacement ratio began to diverge with increasing load. In the descending branch, the shape of the curves indicated that the effect of the RG content on the post-peak behavior of the column was diminished by the lateral reinforcement as the $\rho$ ratio increased: steady curves were recorded from the RG-X-30 series which showed a gentler slope with less RG content, while curves with abrupt change in slopes were recorded from the RG-X-65 and the RG- X-100 series. In case of RG-X-30 series, the specimens shown similar ductility effects until strain 0.03 regardless of RG replacement ratio, but in case of RG-X-65 series, the ductility effects of RAC declined than that of the RG-0-65(0.016) as the minimum 0.0098(RG-100-65) and the maximum 0.0132(RG-30-65) with increasing of RG replacement ratio. In the RG-X-100 series, the strain value of RAC declined than that of RG-0-100(0.095) as the minimum 0.0062(RG-30-100) and the maximum 0.0069(RG-50-100), and it was failure more quickly than RG-0100 specimen. he steepness of the descending curves of the test specimens should correspond to the rate of concrete deterioration mentioned earlier (Figure 4).

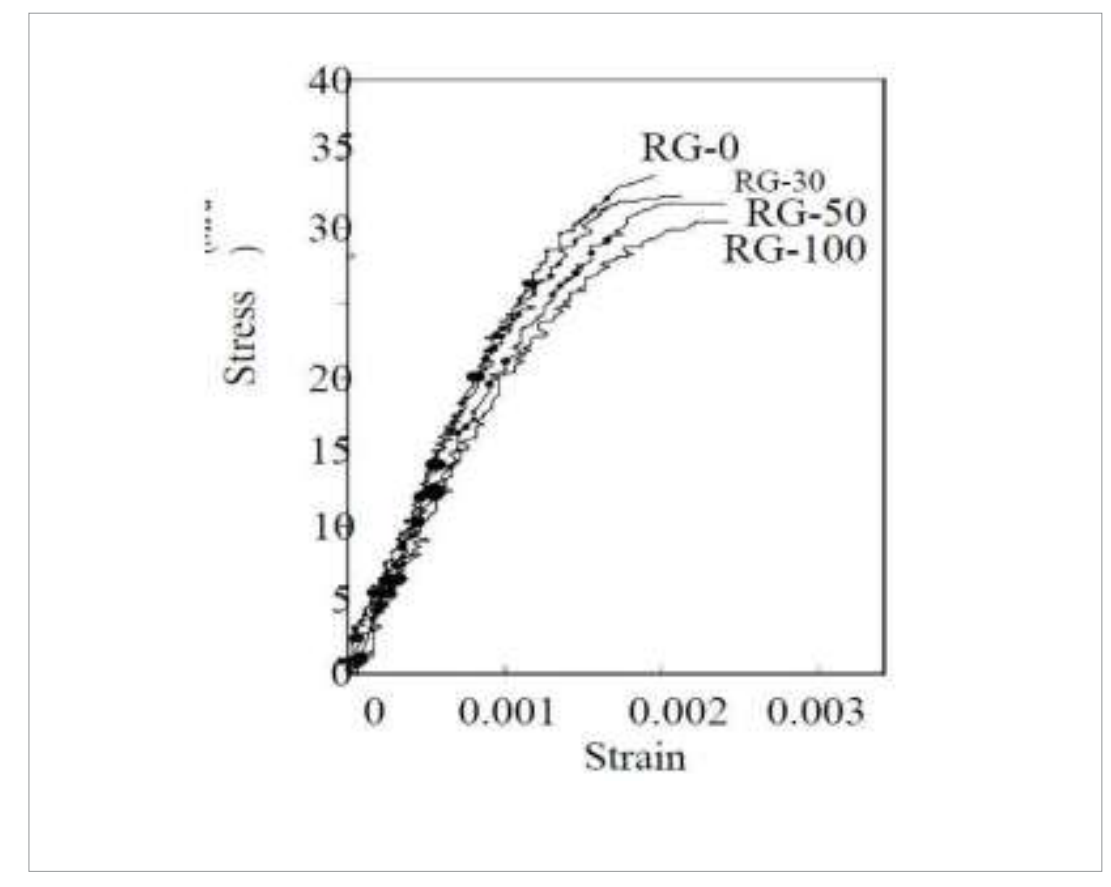

Figure 3:- Stress-strain curve of unconfined concrete cylinder with different RG content. 


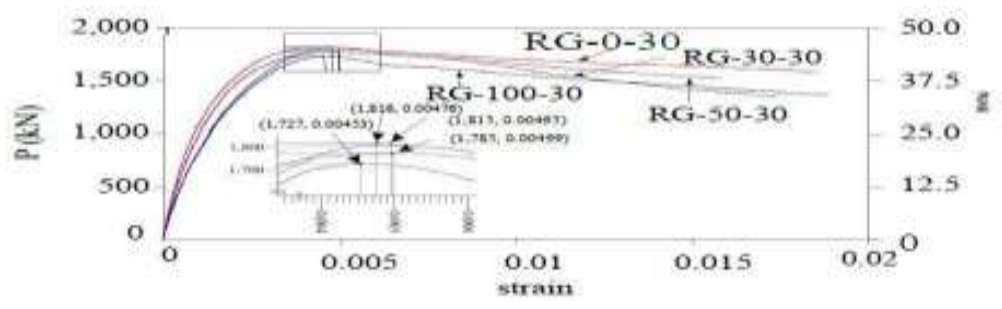

(a)

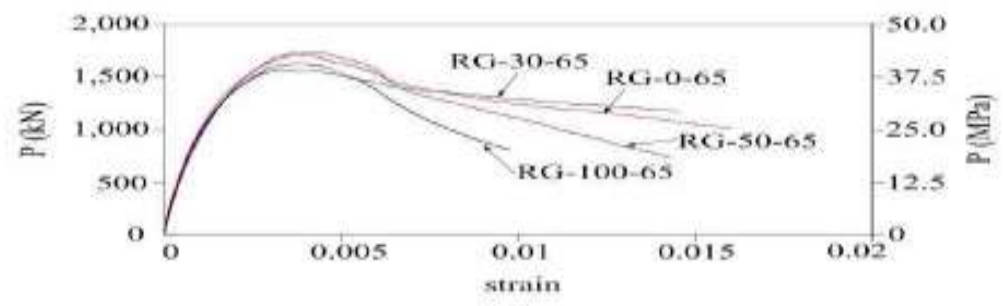

(b)

Figure 4:- An axial load-strain curve of RAC column: tie hoop spacing (a) $=30 \mathrm{~mm},(\mathrm{~b})=65 \mathrm{~mm}$, and (c) $=100 \mathrm{~mm}$

Effect of lateral tie reinforcement ratio ( $\rho$ ) on the confined RG concrete strength and the corresponding strain The effect of $\rho$ on the confined RAC behavior was examined by comparing the slope of the normalized compressive strength ( $\left.f^{\prime} c c / f^{\prime} c o\right)$ and of the normalized corresponding strain $(\varepsilon \mathrm{cc} / \varepsilon \mathrm{co})$ with increasing $\rho$. Figure 6 shows that, for all four RG contents, the strength and strain enhancements of concrete were proportional to $\rho$. he slopes of the fitted curve in Figure 5a indicated that the effect of lateral reinforcement on the strength enhancement was greatest in the RG-30 series, followed in order by RG-100, RG-0, and RG-50. Similarly, the slopes of the fitted curve in Figure 5b indicated that $\rho$ exerted the greatest effect on the strain enhancement in the RG-30 series, followed in order by RG50, RG-0, and RG-100. Although the fitted curves of the RAC showed variations in strength and strain enhancement by lateral reinforcement from those of NAC, the confinement seemed to be effective regardless of the RG replacement ratio over all. For a fixed $\rho$, the strength enhancement due to the tie hoops seemed to increase with increasing RG content (at $\rho=0.004$; f'cc/f'co=1.35 (RG-30), f'cc/f'co=1.38 (RG-50), f'cc/f'co=1.42 (RG-100)). Similarly, the strain enhancement tended to increase with increasing aggregate content (at $\rho=0.006 ; \varepsilon c c / \varepsilon c o=1.48$ (RG-30), $\varepsilon c c / \varepsilon c o=1.53$ (RG-50), $\varepsilon c c / \varepsilon c o=1.59$ (RG-100)) (Figure 6). 

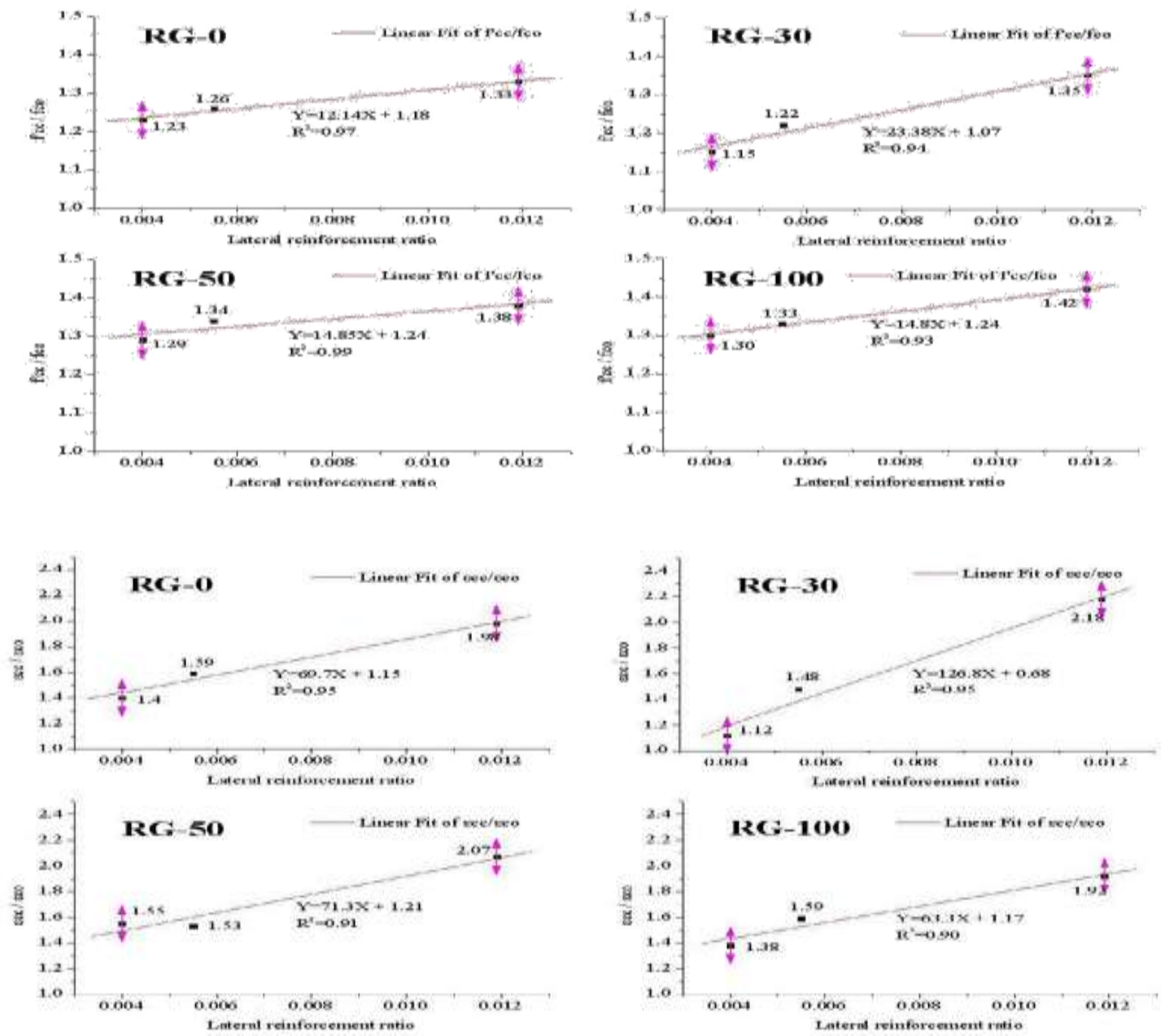

Figure 5:- Effect of lateral reinforcement ratio $(\rho)$ on the enhancement of (a); $f$ cc' and (b); $\varepsilon$ cc with different recycled aggregate contents.

Figure 6:- Comparison between experimental values and those predicted by the modified and existing Mander's model. 
Comparison between the test results and values predicted by the existing confined NAC model

To assess the applicability of the existing compressive confined concrete model to the confined RAC, the experimental values of the confined RAC concrete's compressive strength (f'cc_exp) and corresponding compressive strain (Ecc_exp) at f'cc_exp were compared with the values predicted by the existing model. Mander's model, equations (1) through (3), was selected as it is widely used in practice and in research.

The confinement effectiveness coefficient (ke) value in Equation(3) was calculated according to the method suggested for rectangular concrete sections confined by rectangular hoops with or without cross tie by Mander et al. [14].

$$
\begin{aligned}
& f_{c c}^{\prime}=f_{c c}^{\prime}\left(2.254 \sqrt{1+\frac{7.94 \cdot f_{l}^{\prime}}{f_{c c}^{\prime}}}-\frac{2 \cdot f_{l}^{\prime}}{f_{c c}^{\prime}}-1.254\right) \\
& \varepsilon_{c c}=\varepsilon_{c o}\left[1+5\left(\frac{f_{c c}^{\prime}}{f_{c o}^{\prime}}-1\right)\right] \\
& f_{l}^{\prime}=k_{e} \rho f_{y h}
\end{aligned}
$$

Where, $f^{\prime} c o=$ compressive strength of unconfined concrete; $\varepsilon c o=$ compressive strain of unconfined concrete at $f^{\prime} c o$; $f$ ' $c c=$ compressive strength of confined concrete; $\varepsilon c c=$ compressive strain of confined concrete at $\mathrm{f}$ 'cc; fyh=yield strength of lateral reinforcement; $\mathrm{ke}=$ confinement effectiveness coefficient; $\rho=$ volumetric ratio of transverse steel reinforcement. he ratios of the experimental values to those predicted from the existing model, f'cc_exp/f'cc_model and $\varepsilon c c \_$exp/scc_model, are shown in Table 6 . he average f'cc_exp/f'cc_model and $\varepsilon c c \_e x p / \varepsilon c c \_$model were 0.98 and $0.7 \overline{9}$, with standard deviation of 0.069 and 0.065 , respectively. These results indicated that the existing Mander's model gave the unconservative strength (f'cc) and strain $(\varepsilon \mathrm{cc})$ values for the RAC columns. his may be explained the fact that as Mander's model was originally developed to predict the confined strength and corresponding strain of normal concrete made of natural aggregates, it therefore does not account for different RG replacement ratio in conjunction with different $\rho$. he discrepancy observed between the predicted and experimental values is in agreement with Van Mier [21] and Shah and Ahmad [22], who stated that it is not sufficient to determine the mechanical behavior of confined concrete by parameters such as concrete strength, yield strength and volumetric ratio of the confining reinforcement. The importance of aggregate type was also reported by El-Dash and Ramadan [23], who found that the aggregate type influences the behavior of confined concrete, especially the roundness of the aggregate which assists to distribute the lateral confinement pressure and helps the concrete element to resist higher stress than the angular aggregate. Therefore, as well as the parameters noted above, the type of aggregate and its content shall also be considered in the model (Table 6). he existing model reasonably estimates the compressive strength of the RAC columns with the lateral reinforcement is shown in Figure 6 . he average ratio of f'cc_exp/f'cc model was $0.92,1.01$, and 1.04 for hoop spacing of $30 \mathrm{~mm}, 65 \mathrm{~mm}$, and $100 \mathrm{~mm}$, respectively. However, when the strain at f'cc is considered, Figure 6 clearly shows that the existing model overestimates the $\varepsilon c c$ value by an average of $25 \%, 20 \%$ and $20 \%$ with $30 \mathrm{~mm}, 65 \mathrm{~mm}$ and $100 \mathrm{~mm}$ respectively. In general, the existing equations (1) - (3) tend to overestimate the confined effect of RAC with increasing tie hoop spacing, which renders the existing Mander's model unconservative for use in the design of RAC, especially with high lateral reinforcement. Therefore, the model needs to be modified. Also the f'cc_exp/f'cc_model and $\varepsilon c c \_$exp/ecc_model ratios are proportional to the RG content at a tie hoop spacing of $30 \mathrm{~mm}$. However, this proportionality was no longer evident as the tie hoop spacing was increased to $65 \mathrm{~mm}$ and $100 \mathrm{~mm}$, indicating that the existing model can only be successfully modified by considering effect of $\rho$ that is dependent on the RG replacement ratio. 
Table 6:- Comparison of experiment results to those of the existing model.

\begin{tabular}{|c|c|c|c|c|c|c|}
\hline \multirow[t]{2}{*}{ Specimen } & \multicolumn{3}{|c|}{ Confined strength f'cc (MPa) } & \multicolumn{3}{|c|}{ Confined strain ecc (MPa) } \\
\hline & Exp. & Model & Exp./Model & Exp. & Model & Exp./Model \\
\hline RG-0-30 & 45 & 43.764 & 1.04 & 0.00476 & 0.006377 & 0.75 \\
\hline RG-0-65 & 43 & 38.757 & 1.1 & 0.00382 & 0.005462 & 0.7 \\
\hline RG-0-100 & 41.88 & 37.203 & 1.13 & 0.00339 & 0.005136 & 0.66 \\
\hline RG-30-30 & 45 & 43.148 & 1.05 & 0.00495 & 0.006293 & 0.79 \\
\hline RG-30-65 & 41 & 38.153 & 1.07 & $\mathbf{0 . 0 0 3 3 7}$ & 0.004794 & 0.7 \\
\hline RG-30-100 & 38.45 & 36.601 & 1.05 & 0.00255 & 0.003947 & 0.65 \\
\hline RG-50-30 & 44.63 & 42.017 & 1.06 & 0.00499 & 0.006928 & 0.72 \\
\hline RG-50-65 & 43.45 & 37.046 & 1.17 & 0.00368 & 0.006493 & 0.57 \\
\hline RG-50-100 & 41.93 & 35.497 & 1.18 & 0.00372 & 0.005928 & 0.63 \\
\hline RG-100-30 & 43.18 & 40.059 & 1.08 & 0.00453 & 0.007233 & 0.63 \\
\hline
\end{tabular}

\section{Conclusions:-}

Based on the results of the RAC compressive test and comparison between the test results and the values predicted by the existing model, the following conclusions were drawn:

1. The effect of RG on the compressive confined RAC column was negligible in the ascending branch of the loadstrain curve up to $600 \mathrm{kN}$, which was $35 \%$ of the average confined strength of all specimens tested.

2. Examination of the stress-strain curves indicated that the influence of the RG content increased in both the ascending and descending branches of the stress-strain curves with decreasing $\rho$.

3. The ratios of the experimental values to those predicted from the existing model ( $f^{\prime} c c \_$exp/ $/ f^{\prime} c c$ model) ranged from 1.00 to 1.12 , and the $\varepsilon \mathrm{cc}$ exp/ecc_model ratio from 1.00 to 1.16 . he existing Mander's model tended to give unconservative strength ( $\left.\mathrm{f}^{\prime} \mathrm{cc}\right)$ and strain $(\varepsilon \mathrm{cc})$ values for the RAC columns.

\section{References:-}

1. ACI Committee 555 (2002)

2. Ahmad SH (1994)

3. Brown RL (1928)

4. Chan D (2007)

5. Choi HB (2010)

6. Chung SY (2001).

7. Falkner H (2006)

8. Foster (2001)

9. Giacomo M (2006)

10. Hansen TC (1986)

11. Hisada M (2004)

12. Kang KI (2008)

13. Kang KI (2010)

14. Kikuchi M (1988)

15. Kliszczewicz T (2007)

16. Lam L (2004)

17. Marí A (2006)

18. McKelvey D (2002)

19. Mich (1989).

20. Mohamed RO (2006)

21. Park R (1988(b)

22. Topcu IB (1995)

23. Van Mier JGM (1986) 